\title{
BLENDING BATUBARA UNTUK MEMENUHI KRITERIA PERMINTAAN PASAR EKSPOR
}

\author{
Siti Hardianti ${ }^{1)}$, Yogi Saputra ${ }^{2)}$ \\ 1Program Studi Teknik Pertambangan Batubara Politeknik Akamigas Palembang, 30257, Indonesia \\ 2Program Studi Teknik Pertambangan Batubara Politeknik Akamigas Palembang, 30257, Indonesia \\ Corresponding Author E-mail: siti.hardianti2@gmail.com
}

\begin{abstract}
PT Bukit Asam, Tbk. is one of the companies that conducts coal blending activities to meet market demand, so that coal is sent to consumers according to consumer demand. The blending mechanism used at PT Bukit Asam, Tbk. Tarahan Port Unit is a method of mixing coal using a conveyance with a conveyor by conveyor system.

PT Bukit Asam, Tbk. in the Tarahan Port Unit, it has coal stock in the stockpile in May 2019 amounting to 1,768,356 tons which is used to meet export market demand. In May 2019 PT Bukit Asam, Tbk. The Port Unit exports coal to Fhipina for BB-50, AL-55, AL-62 and AL-72 types of coal as much as 71,500 tons so that the final stock in May 2019 after shipping to the Philippines is 1,696,856 tons. From the results of this analysis coal stock and income can still meet demand in the export market. This is due to the quality and quantity of coal requested by a number of buyer companies fulfilling the terms and conditions. Blending activities in fulfilling the desired coal criteria, the company has been able to meet the demand specifications market.

Keywords: Quality, quantity, blending, final stockpile.
\end{abstract}

Abstrak: PT Bukit Asam, Tbk. adalah salah satu perusahaan yang melakukan kegiatan blending batubara guna memenuhi permintaan pasar, agar batubara yang di kirim ke konsumen sesuai permintaan konsumen. Mekanisme blending yang digunakan di PT Bukit Asam, Tbk. Unit Pelabuhan Tarahan adalah metode pencampuran batubara menggunakan alat angkut dengan sistem conveyor by conveyor. PT Bukit Asam, Tbk. di Unit Pelabuhan Tarahan memiliki stock batubara di stockpile pada bulan Mei 2019 sebesar 1.768 .356 ton yang digunakan untuk memenuhi permintaan pasar ekspor. Pada bulan Mei 2019 PT Bukit Asam, Tbk. Unit Pelabuhan melakukan ekspor batubara ke Filipina untuk jenis batubara BB-50, AL-55, AL-62 dan AL-72 sebanyak 71.500 ton sehingga stock akhir pada bulan mei 2019 setelah pengiriman ke Filipina adalah sebesar 1.696.856 ton. Dari hasil analisis, stock dan pemasukan batubara masih dapat memenuhi permintaan pada pasar ekspor. Hal tersebut disebabkan karena kualitas dan kuantitas batubara yang diminta oleh sejumlah perusahaan pembeli memenuhi syarat dan ketentuan. Kegiatan blending dalam memenuhi kriteria batubara yang dinginkan perusahaan telah mampu memenuhi spesifikasi permintaan pasar.

Kata kunci: Kualitas, kuantitas, blending, stockpile akhir.

\section{PENDAHULUAN}

\subsection{Latar Belakang}

Batubara merupakan salah satu bahan galian yang berpotensi untuk dimanfaaatkan lebih lanjut selain minyak dan gas bumi, batubara pada saat ini lebih banyak digunakan sabagai bahan bakar untuk pembangkit listrik walaupun sebenarnya batubara bermanfaat juga dalam sektor rumah tangga, industri dan transportasi.

Banyaknya jenis pemanfaatan batubara tersebut juga memiliki kriteria batubara yang dibutuhkan untuk memaksimalkan penggunaannya. Oleh karena itu, untuk memenuhi kebutuhan konsumen tersebut, batubara yang diproduksi harus sesuai dengan syarat atau spesifikasi kualitas seperti kandungan air, kandungan abu, zat terbang, nilai kalori dan sulfur yang diinginkan pasar dengan jumlah produksi batubara juga harus memenuhi permintaan pasar, namun dalam pemenuhan kebutuhan tersebut, masih terdapat kendala antara lain kadar abu, sulfur dan moisture batubara yang mengalami perubahan kualitas.

Blending batubara adalah proses untuk memenuhi permintaan konsumen dan agar batubara dengan kualitas rendah dapat bernilai ekonomis (Suparny, 2016). PT Bukit Asam, Tbk. adalah salah satu perusahaan yang melakukan kegiatan blending batubara guna memenuhi permintaan pasar agar batubara yang di kirim sesuai permintaan konsumen, selain itu PT Bukit Asam, Tbk. juga menerapkan sistem mine brand untuk batubara hasil dari front penambangan dan market 
brand untuk batubara yang siap dijual, bila mine brand telah memenuhi spesifikasi permintaan maka batubara tersebut dapat langsung dikirim ke konsumen dengan kode pengiriman BA (Bukit Asam), apabila spesifikasi tidak sesuai dengan permintaan pasar, maka dilakukan blending untuk mengatasi permasalahan spesifikasi batubara yang tidak sesuai dengan permintaan konsumen.

Berdasarkan latar belakang tersebut penulis melakukan penelitian mengenai blending batubara untuk memenuhi kriteria permintaan pasar, khususnya pasar ekspor di PT Bukit Asam, Tbk. Unit Pelabuhan Tarahan.

\subsection{Rumusan Masalah}

Penelitian ini dilakukan karena adanya permasalahan mengenai bagaimana proporsi blending yang tepat untuk memenuhi spesifikasi batubara pasar ekspor tujuan Filipina pada bulan Mei 2019 serta bagaimana stock akhir batubara pada bulan tersebut.

\subsection{Batasan Masalah}

Batasan masalah dalam penelitian ini adalah bagaimana mekanisme proporsi blending batubara pasar ekpsort tujuan Filipina pada bulai Mei 2019 dan analisis stock akhir guna menghemat penggunaan batubara peringkat tinggi dan mengoptimalkan penggunaan batubara peringkat rendah serta memakai batubara yang belum terpakai sehingga dapat memenimalisir lama timbunan untuk stock yang belum terpakai.

\subsection{Tujuan Penelitian}

Tujuan penelitian ini adalah :

1. Dapat menentukan proporsi blending batubara untuk memenuhi pengiriman kebutuhan ekspor batubara tujuan Filiphina pada bulan Mei 2019 di PT Bukit Asam, Tbk. Unit Pelabuhan Tarahan, dan realisasinya.

2. Dapat menganalisis stock akhir batubara pengiriman bulan Mei 2019 pada stockpile yang ada di PT Bukit Asam, Tbk. Unit Pelabuhan Tarahan.

\subsection{Manfaat Penelitian}

Tujuan dalam penelitian ini adalah :

1. Dapat mengetahui optimalisasi realisasi proporsi batubara peringkat rendah karena penggunaan batubara peringkat rendah sangat sulit digunakan apabila tidak diadakannya kegiatan blending.

2. Mengetahui stock akhir batubara pada stockpile yang ada di PT Bukit Asam, Tbk. Unit Pelabuhan Tarahan pada bulan Mei 2019.

\section{TEORI DASAR}

\subsection{Parameter Kualitas Batubara}

Menurut ASTM D3173/ American Society of Testing and Materials (2002), kandungan di dalam komponen batubara menentukan besarnya nilai panas yang akan dihasilkan, kualitas batubara dapat ditentukan oleh beberapa parameter yang terkandung dalam batubara.

1. Kandungan Air (Total Moisture)

Kandungan air total adalah banyaknya air yang terkandung dalam batubara sesuai dengan kondisi lapangan, kandungan air total sangat dipengaruhi oleh ukuran butir batubara dan cuaca daerah sekitar, yang dinyatakan dalam $\%$ dan dasar pelaporan dari batubara dalam keadaan insitu (ar).

2. Kandungan Air Bebas (Free Moisture) Kandungan air bebas merupakan air yang berada dipermukaan batubara akibat pengaruh dari luar seperti cuaca.

3. Kandungan Air Bawaan (Inherent Moisture)

Kandungan air bawaan merupakan kandungan air yang ada pada batubara bersama dengan saat terbentuknya batubara tersebut, kandungan air bawaan berhubungan erat dengan nilai kalori, umumnya bila kandungan air bawaan berkurang maka nilai kalori meningkat demikian juga sebaliknya, dasar pelaporan dalam kondisi bebas air permukaan (adb).

4. Kandungan Abu (Ash Content)

Kandungan abu merupakan sisa-sisa zat anorganik yang terkandung dalam 
batubara setelah dibakar, kandungan abu tersebut dapat dihasilkan dari pengotor bawaan dalam proses pembentukan batubara maupun dari proses penambangan, dasar pelaporan dalam kondisi bebas air permukaan (adb).

5. Zat Terbang (Volatile Matter)

Zat terbang merupakan zat aktif yang terdapat pada batubara yang menghasilkan energi atau panas apabila batubara tersebut dibakar, sehingga zat terbang merupakan zat aktif yang mempercepat proses pembakaran, zat terbang tersebut terdiri dari gas-gas yang mudah terbakar seperti hidrogen $(\mathrm{H})$, karbon monoksida (CO) dan metana $\left(\mathrm{CH}_{4}\right)$, dasar pelaporan dalam kondisi bebas air permukaan (adb).

6. Karbon Tertambat (Fixed Carbon)

Fixed carbon atau kadar karbon merupakan kandungan utama dari batubara, kandungan inilah yang paling berperan dalam menentukan besarnya heating value suatu batubara, semakin besar nilai fixed carbon, maka semakin besar heating value-nya, nilai kadar karbon diperoleh melalui pengurangan angka 100 dengan jumlah kadar kandungan air (moisture), kadar abu (ash) dan jumlah zat terbang (volatile matter), rasio fixed carbon dengan volatile matter (zat terbang) disebut dengan "FR" (Fuel Ratio), Fuel Ratio juga dapat digunakan sebagai pegangan untuk menentukan peringkat batubara.

7. Kandungan Sulfur (Total Sulfur)

Untuk mengetahui kandungan total sulfur yang terdapat pada batubara dengan membakar sampel batubara pada suhu tinggi $\left( \pm 1350^{\circ}\right)$ yang dinyatakan dalam bentuk \%, pada dasar pelaporan dalam kondisi bebas air permukaan $(\mathrm{adb})$. Sulfur yang terdapat dalam batubara yaitu sulfur piritik $\left(\mathrm{FeS}_{2}\right)$ biasanya berjumlah $20-80 \%$ dari total sulfur dan berasosiasi dengan abu batubara. Sulfur organik biasanya berjumlah relatif dan bervariasi antara
20-80 \% dari total sulfur, sulfur organik terikat secara kimia dengan substansi atau zat lain dan sulfat sebagian besar terdiri dari kalsium sulfat dan besi sulfat.

8. Nilai Kalori (Calorific Value)

Nilai kalori dari batubara merupakan jumlah panas dari komponen yang terbakar dari batubara seperti karbon, hidrogen dan sulfur dikurangi dengan panas reaksi eksotermis atau endotermis yang terjadi dari pembakaran komponen pengotor. GCV adalah analisis yang mengikutsertakan kalor latern (kalori yang menguapkan air), HHV adalah analisis yang tidak mengikut sertakan kalor latern..

\subsection{Pencampuran Batubara (Coal Blending)}

Blending atau pencampuran batubara merupakan proses untuk pemanfaatan batubara kualitas rendah yang dicampur dengan batubara kualitas tinggi, dengan menggunakan dua jenis batubara atau lebih. Hasil dari blending ini digunakan untuk memenuhi permintaan konsumen, blending ini juga harus memperhatikan parameter yang sesuai dengan spesifikasi atau standar yang telah ditetepakan.

Dalam melakukan blending dapat dilakukan dengan mengkalkulasi kualitas dan kuantitas blending dengan menggunakan rumusan sebagai berikut :

$\mathrm{QB}=\left(\mathrm{Q}_{1} \times \mathrm{W}_{1}\right)+\left(\mathrm{Q}_{2} \times \mathrm{W}_{2}\right)+\cdots\left(\mathrm{Q}_{\mathrm{n}} \times \mathrm{W}_{\mathrm{n}}\right)$

Dimana :

$$
\left(\mathrm{W}_{1}+\mathrm{W}_{2}\right)+\cdots\left(\mathrm{W}_{\mathrm{n}}+\mathrm{W}_{\mathrm{n}}\right)
$$

$\mathrm{QB}=$ kualitas hasil blending

$\mathrm{Q}_{1}=$ kualitas batubara $1(\mathrm{kkal} / \mathrm{kg})$

$\mathrm{Q}_{2}=$ kualitas batubara $2(\mathrm{kkal} / \mathrm{kg})$

$\mathrm{Q}_{\mathrm{n}}=$ kualitas batubara $\mathrm{n}$

$\mathrm{W}_{1}=$ kuantitas batubara 1 (ton)

$\mathrm{W}_{2}=$ kuantitas batubara 2 (ton)

$\mathrm{W}_{\mathrm{n}}=$ kuantitas batubara $\mathrm{n}$ 
Berdasarkan observasi lapangan di PT Bukit Asam, Tbk. Unit Pelabuhan Tarahan hal yang menjadi perhatian dalam penanganan blending, sebagai berikut:

1. Hasil suatu blending yang homogen sangat diperlukan terutama untuk konsumen.

2. Ketidak-homogenan dalam suatu blending akibatnya akan terasa langsung oleh konsumen pada saat batubara itu dipakai.

3. Kesempurnaan dari suatu blending adalah ketepatan dalam pencapaian target kualitas hasil blending dan homogenitas hasil blending.

Dengan demikian, maka faktor yang menentukan kualitas blending yaitu proporsi blending yang akurat, sistem blending yang baik, terkontrol dan perhitungan hasil blending yang terkonsep sesuai dengan tipe parameter yang benar.

\subsection{Metode Pencampuran Batubara}

Metode pencampuran atau blending batubara yang digunakan di PT Bukit Asam, Tbk. Unit Pelabuhan Tarahan adalah metode blending conveyor by conveyor. Blending conveyor by conveyor adalah metode blending dimana terdapat dua atau lebih conveyor yang mengangkut batubara untuk dicampur pada suatu tempat. Batubara yang diangkut oleh suatu conveyor akan dicurahkan pada suatu tempat kemudian akan dicampur dengan batubara hasil curahan dari conveyor lain. Metode ini merupakan metode yang digunakan di Pelabuhan Tarahan, metode ini dianggap metode paling efisien untuk digunakan di Pelabuhan Tarahan pada saat ini (Gambar 2.1).

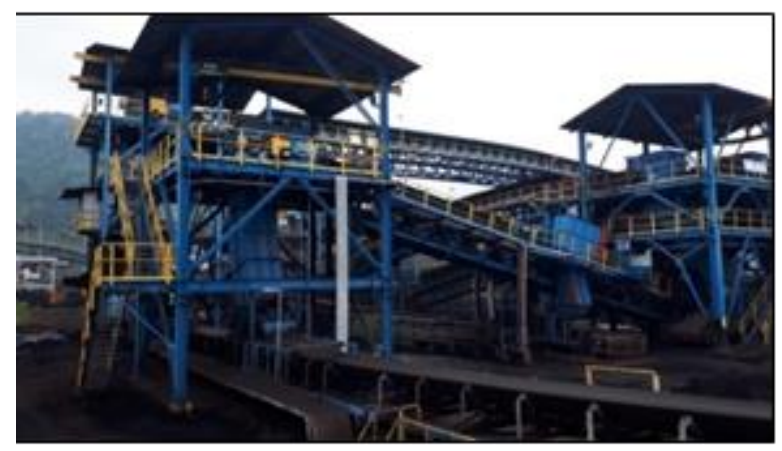

Gambar 2.1 Blending Conveyor by Conveyor

\subsection{Angkutan Batubara}

Berdasarkan observasi lapangan pengangkutan batubara merupakan unsur yang sangat penting dalam usaha penambangan batubara. Karena mayoritas kegiatan usaha ini memindahkan hasil produksi dari lokasi tambang sampai lokasi end-user. Berdasarkan sarana pengangkutan batubara dikelompokkan menjadi tiga jenis angkutan. Angkutan berupa angkutan darat, angkutan laut dan angkutan sungai.

\subsubsection{Angkutan Darat}

Biasanya alat yang digunakan untuk mengangkut batubara pada jalur darat, yaitu belt conveyor, dump truck dan kereta api.

1. Belt conveyor

Pengangkutan ini biasanya digunakan untuk pengangkutan dengan jarak relatif lebih dekat dan biasanya berada di areal tambang. Namun, kecepatan alat dapat diatur dengan sesuai kapasitas tambang sehingga proses produksi batubara lebih efisien. Belt conveyor ini digunakan di Pelabuhan Tarahan dengan panjang \pm 500 meter dari tempat pembongkaran batubara. Batubara dibongkar dari gerbong kereta api melalui RCD setelah dibongkar batubara masuk ke dalam tempat aprond feeder menuju belt conveyor setelah itu, belt conveyor akan berjalan sampai ke primary crusher kemudian ke kompayer, SR, beltplught, triper cars, di tumpuk ke stockpile dan dari stockpile ditransfer melalui aprond tunel ke belt menuju shiploader atau barge loader didekat tongkang. Alat angkut ini digunakan di Pelabuhan Tarahan dianggap sangat efisen dan efektif untuk digunakan

2. Dump truck

Pengangkutan dengan dump truck membutuhkan alat lain, yaitu excavator. Dimana alat ini digunakan untuk waktu pemuatan batubara (loading). Jika dump truck digunakan dikawasan tambang ukurannya lebih fleksibel (tidak ada ikatan peraturan), tapi jika dump truck digunakan diluar tambang maka kapasitasnya harus sesuai dengan aturan pemerintah. 
Misalnya, batas jumlah muatan, ukuran, spesifikasi dan jalan yang dilalui. Alat angkut ini tidak digunakan di Pelabuhan Tarahan tapi hanya untuk mengangkut batubara dari stockpile 1 menuju PLTU yang berada di samping Pelabuhan Tarahan

\section{Kereta api}

Pengangkutan jenis ini tidak mengganggu lalu lintas jalan umum, sehingga waktu pendistribusiannya lebih cepat. Namun, biaya yang dikeluarkan relatif lebih besar dibandingkan dengan menggunakan dump truck. Alat angkut ini digunakan untuk mengangkut batubara dari Unit Pertambangan Tanjung Enim sampai ke Pelabuhan Tarahan, untuk tiap gerbong yang digunakan terisi 50 ton batubara dan dalam satu rangkaian ratarata memiliki 60 gerbong

\subsubsection{Angkutan Laut}

Pengangkutan batubara dengan menggunakan kapal atau tongkang yang ditarik dengan menggunakan kapal tunda. Hambatan yang dihadapi dalam pengangkutan ini adalah cuaca buruk yang menyebabkan tertundanya pengiriman kepada pembeli. Keuntungannya adalah lebih ekonomis dan biaya relatif lebih rendah dibandingkan angkutan darat. Metode ini digunakan di Pelabuhan Tarahan karena alat angkut ini memiliki panjang dan lebar yang sangat besar sehingga dapat banyak menampung batubara yang untuk di kirim, dan Pelabuhan Tarahan cocok menggunakan angkutan kapal karena pelabuhan tarahan memang didesain untuk melayani permintaan konsumen dalam jumlah yang relatif banyak, baik dalam ataupun luar negeri, di pelabuhan Tarahan biasanya kapal yang relatif besar berlabuh ke jetty 3 , kemudian untuk jetty 1 biasanya untuk tongkang

\subsubsection{Angkutan Sungai}

Pengangkutan sungai biasanya menggunakan barge sebagai sarana pengangkutan batubara, sungai yang dilalui harus lebih lebar dan berarus (debit air besar). Keuntungan dari pengangkutan ini yaitu dapat mengangkut lebih banyak jumlah batubara, alat angkut ini juga digunakan di Pelabuhan Tarahan karena alat angkut ini memiliki panjang dan lebar yang tidak terlalu besar sehingga mudah untuk dilabuhkan, di pelabuhan Tarahan tongkang ini di labuhkan hanya pada jetty satu dan dua karena jetty tersebut memang di peruntukan pengisian yang lebih kecil dari jetty 3, gambar pengisian tongkang di jetty 1 Pelabuhan Tarahan.

\section{METODOLOGI PENELITIAN}

\subsection{Jenis Penelitian}

Penelitian ini merupakan penelitian deskriptif kuantitatif yaitu penelitian yang dilakukan untuk mengetahui nilai variabel mandiri, baik satu variabel atau lebih tanpa membuat perbandingan, atau menghubungkan dengan variabel lain, data yang diperoleh dari sampel populasi penelitian dianalisis sesuai dengan metode statistik yang digunakan kemudian diinterpretasikan

\subsection{Waktu dan Tempat Penelitian}

Penelitian ini dilakukan pada tanggal 08 Mei sampai 05 Juli 2019. Penelitian ini dilakukan di PT Bukit Asam, Tbk. Unit Pelabuhan Tarahan di Satuan Kerja Kendali Produk.

\subsection{Metode Penelitian}

Masalah-masalah yang dibahas pada penelitian ini, dapat menggunakan beberapa metode penyelesaiannya sebagai berikut: Penulis menggabungkan antara studi pustaka dengan data-data observasi lapangan. Urutan pekerjaan penelitian, yaitu :

1. Studi literatur

Studi literatur adalah sumber-sumber data yang dapat digunakan sebagai data awalan terhadap penelitian yang akan dilakukan di stockpile, dimulai dari batubara masuk ke dalam stockpile hingga keluar, serta situasi stockpile, dan lain-lain.

2. Observasi lapangan

Pengamatan terhadap kegiatan yang berkaitan dengan batasan masalah yang ada.

3. Pengumpulan Data

Dalam penelitian ini terdapat dua jenis data, yaitu : 
1. Data primer, data yang dikumpulkan secara langsung dilapangan. Data yang diambil berupa data rata-rata kualitas batubara ekspor tiap stockpile.

2. Data sekunder, yaitu data yang diambil dari data yang sudah ada di perusahaan dan referensi-referensi yang berhubungan dengan penelitian ini.

Pengambilan datanya meliputi :

a. Data kualitas batubara mine brand.

b. Data stock batubara yang masuk dan keluar di stockpile.

c. Data kualitas dan kuantitas batubara market brand.

d. Data dan spesifikasi batubara permintaan pasar.

e. Data rata-rata kualitas batubara ekspor tiap stockpile.

4. Pengolahan dan Analisis Data

Pengolahan data dilakukan dengan beberapa perhitungan yang selanjutnya akan direalisasikan dalam bentuk tabel.

Perhitungan meliputi :

1. Menghitung stock awal batubara di stockpile

Stock Awal Seluruh = Stock Awal +

Pemasukan Batubara)

2. Perhitungan proporsi blending antara, batubara yang berbeda kualitas agar hasilnya optimal

$\mathrm{QB}=(\mathrm{Q} 1 \times \mathrm{W} 1)+(\mathrm{Q} 2 \times \mathrm{W} 2)+\cdots(\mathrm{Qn} \times \mathrm{Wn})$

$(\mathrm{W} 1+\mathrm{W} 2)+\cdots(\mathrm{Wn}+\mathrm{Wn})$

3. Perhitungan batubara yang digunakan kemudian ditambah dengan batubara pemasukan dari Tanjung Enim

Stock Sisa $=($ Stock Awal Pengeluaran) + Pemasukan....(3.3)

4. Perhitungan stock akhir, setelah blending dilakukan untuk mengetahui sisa batubara di stockpile setelah pengiriman
Stock Akhir $=$ Stock Awal Seluruh Pengeluaran Seluruh).

5. Analisis parameter kualitas batubara hasil blending

Setelah dilakukan blending, kemudin dilakukan analisis terhadap batubara hasil blending. Hal ini bertujuan untuk mengetahui parameter hasil blending yang sudah memenuhi persyaratan permintaan pasar atau tidak.

6. Analisis stock akhir

Untuk mendapatkan nilai kualitas batubara yang ada di stockpile sisa dari pengiriman, apakah batubara di stockpile dapat memenuhi kualitas yang diminta oleh pasar untuk pengiriman selanjutnya.

\section{HASIL DAN PEMBAHASAN}

\subsection{Kualitas Batubara Mine Brand PT.} Bukit Asam,Tbk.

Secara keseluruhan di setiap lokasi penambangan memiliki nilai kalori yang berbeda dan memiliki mine brand tersendiri. Di PT. Bukit Asam, Tbk, mine brand batubara dibedakan berdasarkan nilai kalorinya. Mine brand PT. Bukit Asam, Tbk. memiliki tiga lokasi penambangannya yaitu BB untuk Bangko Barat, AL untuk Air Laya, dan MT untuk Muara Tiga Besar (Tabel 4.1)

Tabel 4.1 Parameter Kualitas Batubara Mine Brand PT. Bukit Asam, Tbk

\begin{tabular}{|c|c|c|c|c|c|c|c|c|}
\hline \multirow[b]{2}{*}{$\begin{array}{l}\text { Mine } \\
\text { Brand }\end{array}$} & \multicolumn{8}{|c|}{ Parameter } \\
\hline & $\begin{array}{c}\text { Total } \\
\text { Moisture } \\
(96 a r)\end{array}$ & $\begin{array}{l}\text { Inhererent } \\
\text { Moisture } \\
\text { (96adb) }\end{array}$ & $\begin{array}{l}\text { Ash } \\
\text { (96ar) }\end{array}$ & $\begin{array}{l}\text { Volatile } \\
\text { Matter } \\
\text { (96ar) }\end{array}$ & $\begin{array}{l}\text { Fixed } \\
\text { Carbon } \\
\text { (96ar) }\end{array}$ & $\begin{array}{l}\text { Sulphur } \\
\text { (9aar) }\end{array}$ & $\begin{array}{c}\text { Calorific } \\
\text { Value } \\
\text { (Kkal/Kgar) }\end{array}$ & $\begin{array}{c}C V \\
(K k a l / K g \\
A d b)\end{array}$ \\
\hline BB-50 & 24,15 & 15,79 & 6,38 & 32,86 & 36,61 & 0.61 & 5.000 & 5.551 \\
\hline BB-52 & - & - & - & - & - & - & - & - \\
\hline MT-44 & 28,91 & 13,25 & 6.96 & 32,72 & 31,41 & 0,56 & 4.400 & 5.369 \\
\hline MT -46 & 27,79 & 13,59 & 4,13 & 33,72 & 33,37 & 0,39 & 4.601 & 5.506 \\
\hline MT-50 & 25,58 & 12,75 & 3,98 & 34,92 & 35,52 & 0.59 & 5.000 & 5.862 \\
\hline AL-50 & 25,83 & 13,03 & 4,31 & 34,44 & 35,42 & 0,61 & 5.000 & 5.807 \\
\hline AL-52 & - & - & - & - & - & - & - & - \\
\hline AL-55 & - & - & - & - & - & - & - & - \\
\hline AL-58 & 17,92 & 9,32 & 3,63 & 37,92 & 40,54 & 0,73 & 5.801 & 6.409 \\
\hline AL-61 & - & - & - & - & - & - & - & - \\
\hline AL-64 & 11,47 & 5,05 & 4,88 & 37,97 & 45,66 & 0,90 & 6.400 & 7.433 \\
\hline AL-67 & 8,95 & 4,09 & 4,76 & 37,72 & 48,57 & 0,87 & 6.700 & 7.057 \\
\hline AL 72 & 6.68 & 2,78 & 5,17 & 35.92 & 52,22 & 0.78 & 7.200 & 7.501 \\
\hline
\end{tabular}


Tabel 4.2 Rata-Rata Kualitas Batubara Hasil Sampel di Pelabuhan Tarahan Bulan Mei 2019

\begin{tabular}{|c|c|c|c|c|c|c|c|c|}
\hline \multirow[b]{2}{*}{$\begin{array}{l}\text { Mine } \\
\text { Brand }\end{array}$} & \multicolumn{8}{|c|}{ Parameter } \\
\hline & $\begin{array}{c}\text { Total } \\
\text { Moisture } \\
\text { (\%ar) }\end{array}$ & $\begin{array}{c}\text { Inhererent } \\
\text { Moisture } \\
(\% a d b)\end{array}$ & $\begin{array}{c}\text { Ash } \\
(\% \text { ar })\end{array}$ & $\begin{array}{l}\text { Volatile } \\
\text { Matter } \\
\text { (\%ar) }\end{array}$ & $\begin{array}{l}\text { Fixed } \\
\text { Carbon } \\
(\% \text { ar })\end{array}$ & $\begin{array}{l}\text { Sulphur } \\
(\% a r)\end{array}$ & $\begin{array}{c}\text { Calorific } \\
\text { Value } \\
\text { (Kkal/Kg,ar) }\end{array}$ & $\begin{array}{c}C V \\
(k k a l k g \\
A d b)\end{array}$ \\
\hline BAS-48 & 30,02 & 15,53 & 5,94 & 38,40 & 40,14 & 0,56 & 4.790 & 5.782 \\
\hline BB-50 & 28,80 & 15,34 & 6,00 & 37,71 & 40,95 & 0,50 & 4.930 & 5.861 \\
\hline AL-52 & 23,82 & 13,14 & 3,56 & 41,48 & 41,83 & 0,74 & 5.466 & 6.232 \\
\hline AL-55 & 20,64 & 12,15 & 4,31 & 39,01 & 44,53 & 1,25 & 5.804 & 6.425 \\
\hline AL-64 & 9,20 & 6,21 & 6,29 & 39,13 & 48,37 & 0,80 & 6.499 & 6.945 \\
\hline AL-67 & 8,03 & 3,27 & 6,86 & 26,12 & 63,75 & 0,84 & 7.154 & 7.525 \\
\hline AL 72 & 7,11 & 2,44 & 5,53 & 24,47 & 67,57 & 0,64 & 7.472 & 7.848 \\
\hline
\end{tabular}

\subsection{Kualitas Batubara Market Brand PT Bukit Asam, Tbk.}

Market brand adalah hasil yang siap untuk dipasarkan dilihat dari kualitas batubara yang telah memenuhi spesifikasi kualitas. Jika spesifikasi kualitas batubara tidak sama dengan permintaan pasar maka akan dilakukan proses blending untuk mendapatkan kualitas yang diinginkan oleh konsumen. Penjualan Market Brand batubara di Pelabuhan Tarahan untuk pasar ekspor bulan Mei 2019 berupa BA 45,48,50,55,64, GAR 6100, untuk Market Brand GAR 6100 parameternya situasional sesuai permintaan konsumen, market brand ekspor tersebut cuma ada enam karena sesuai dengan RKAP bulan Mei 2019, namun dalam penelitian ini saya hanya membahas pengiriman GAR 6100 saja. Berikut spesifikasi market brand batubara PT Bukit Asam, Tbk berdasarkan analisis yang terdapat dilaboratorium (Tabel 4.3).

Tabel 4.3 Parameter Kualitas Batubara Market Brand PT Bukit Asam, Tbk.

\begin{tabular}{|c|c|c|c|c|c|c|c|c|}
\hline \multirow{2}{*}{$\begin{array}{c}\text { Market } \\
\text { Brand }\end{array}$} & \multicolumn{7}{|c|}{ Parameter } \\
\cline { 2 - 9 } & TM & IM & Ash & VM & FC & TS & \multicolumn{2}{|c|}{$\begin{array}{c}\text { GCV } \\
\text { (kkal/kg) }\end{array}$} \\
\cline { 2 - 9 } & (ar) & (adb) & (ar) & (ar) & (ar) & (ar) & (adb) & (ar) \\
\hline $\begin{array}{c}\text { GAR } \\
6100\end{array}$ & $\begin{array}{c}17,78 \\
\text { (arb) }\end{array}$ & 4,55 & - & - & - & $\begin{array}{c}1,00 \\
(\mathrm{Max})\end{array}$ & 6.990 & 6.100 \\
\hline
\end{tabular}

\subsection{Stock Batubara pada Stockpile Tarahan Periode Bulan Mei 2019}

Stockpile awal batubara tiap pengiriman bulan Mei 2019 merupakan sisa dari pengiriman sebelumnya, stockpile di Pelabuhan Tarahan ada empat, yaitu stockpile satu, stockpile dua, stockpile tiga, dan stockpile empat. Setiap stockpile dapat menampung dua jenis batubara atau lebih, stockpile batubara Pelabuhan Tarahan terdiri beberapa jenis batubara, kurang lebih terdiri dari lima belas jenis Batubara, jenis-jenis tersebut antara lain BAS 48, BB 50, BB 52, MT 44, MT 46, MT 50, AL 50, AL 52, AL 55, AL 58, AL 61, AL 64, AL 67, AL 72, stockpile ini dibedakan berdasarkan jenis batubara yang cuma digunakan dalam pengiriman agar memudahkan pembacaan pada saat akan di lakukan proses pencampuran (Tabel 4.4).

Tabel 4.4 Stock Batubara di Stockpile Awal Bulan Mei 2019

\begin{tabular}{|c|c|c|}
\hline No. & Jenis Mine Brand & Tonase (ton) \\
\hline 1 & BAS 48 & 11.233 \\
\hline 2 & BB 50 & 8.460 \\
\hline 3 & AL 52 & 0 \\
\hline 4 & AL 55 & 10.000 \\
\hline 5 & AL 67 & 0 \\
\hline 6 & AL 72 & 65.854 \\
\hline \multicolumn{3}{|c|}{ Total } \\
\hline
\end{tabular}

4.4 Skema Proporsi dan Pemuatan untuk Memenuhi Permintaan Pasar Ekspor Mei 2019

Untuk memenuhi permintaan Pasar Ekspor pada bulan Mei 2019, khususnya Perusahaan Galaxy tujuan Filipina maka dibuatlah skema proporsi seperti gambar 4.1.

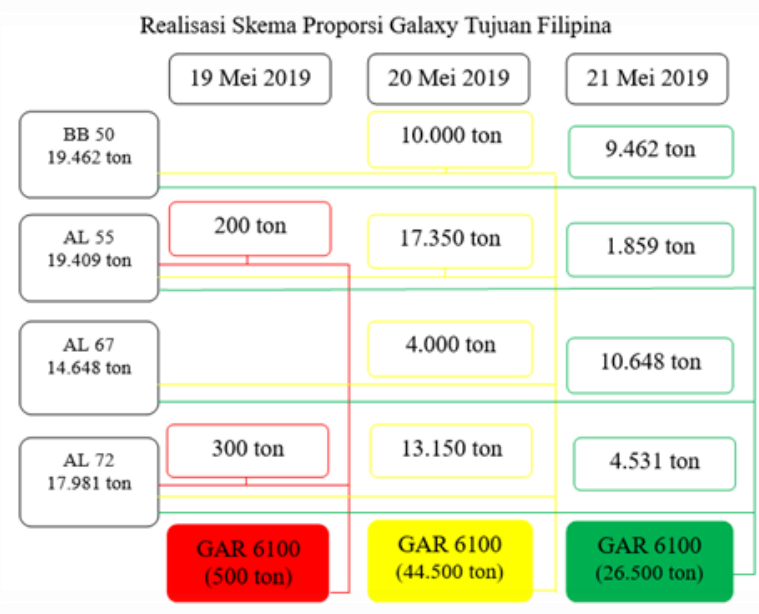

Gambar 4.1 Skema Proporsi untuk Perusahaan Galaxy Tujuan Filipina 
Berdasarkan Gambar 4.1 pemuatan batubara untuk pengiriman Filipina dapat dijelaskan melalui tiga warna, skema garis merah, kuning dan hijau. Warna merah pada gambar tersebut menjelaskan bahwa skema untuk pemuatan hari pertama, warna kuning menjelaskan untuk pemuatan hari kedua dan untuk warna garis yang berwarna hijau merupakan pemuatan hari ketiga atau terakhir untuk Galaxy tujuan Filipina pada bulan Mei 2019

\subsection{Stockpile Awal Pengiriman Pertama untuk Perusahaan Galaxy Tujuan Filipina}

Pemuatan Batubara hari pertama Galaxy tujuan Filipina dilakukan pada tanggal 19 Mei 2019 maka untuk perhitungan stock awal pengiriman dimulai dari tanggal $01 \mathrm{~s} / \mathrm{d}$ 18 mei 2019 dengan rincian sebagai berikut (Tabel 4.5).

Tabel 4.4 Stock Awal dan Pemasukan

\begin{tabular}{|c|c|c|c|c|c|c|}
\hline Parameter & \multicolumn{5}{|c|}{ Mine Brand } \\
\hline \hline Pemasukan & $\begin{array}{c}\text { BAS-48 } \\
\text { (ton) }\end{array}$ & $\begin{array}{c}\text { BB-50 } \\
\text { (ton) }\end{array}$ & $\begin{array}{c}\text { AL-52 } \\
\text { (ton) }\end{array}$ & $\begin{array}{c}\text { AL-55 } \\
\text { (ton) }\end{array}$ & $\begin{array}{c}\text { AL-67 } \\
\text { (ton) }\end{array}$ & $\begin{array}{c}\text { AL-72 } \\
\text { (ton) }\end{array}$ \\
\hline $\begin{array}{c}\text { Stock awal } \\
\text { (31-Apri-019) }\end{array}$ & 11.233 & 8.460 & - & 10.909 & - & 65.854 \\
\hline 01-Mei-19 & 11.850 & 25.900 & - & - & 5.100 & 4.200 \\
\hline 02-Mei-19 & 12.000 & 36.500 & - & - & - & 6.700 \\
\hline 03-Mei-19 & 16.850 & 20.450 & - & 3.000 & 8.950 & - \\
\hline 04-Mei-19 & 15.700 & 18.300 & 1.250 & - & 2.950 & 7.450 \\
\hline 05-Mei-19 & 21.250 & 32.950 & - & - & - & 3.300 \\
\hline 06-Mei-19 & 15.700 & 24.450 & - & - & 6.000 & 6.000 \\
\hline 07-Mei-19 & 9.600 & 28.250 & - & - & 3000 & 1.400 \\
\hline 08-Mei-19 & 17.350 & 25.650 & 3.000 & 3.000 & - & 16.600 \\
\hline 09-Mei-19 & 20.700 & 30.650 & 3.000 & - & - & 3.000 \\
\hline 10-Mei-19 & 23.500 & 43.250 & 3.000 & - & - & 3.000 \\
\hline 11-Mei-19 & 3.800 & 12.850 & - & - & - & - \\
\hline 12-Mei-19 & 20.700 & 20.600 & 3.000 & - & - & 1.550 \\
\hline 13-Mei-19 & 15.000 & 25.350 & 6.000 & - & - & 8.450 \\
\hline 14-Mei-19 & 16.500 & 25.850 & 5.500 & - & 9.000 & 14.200 \\
\hline 15-Mei-19 & 35.900 & 31.900 & 1.250 & - & 9.300 & 8.750 \\
\hline 16-Mei-19 & 11.950 & 37.550 & - & - & 9.250 & - \\
\hline 17-Mei-19 & 5.400 & 6.050 & - & - & 5.000 & - \\
\hline 18-Mei-19 & 14.100 & 22.750 & 6.000 & - & 15.950 & - \\
\hline Total & 299.083 & 477.710 & 32.000 & 16.909 & 74.500 & 150.454 \\
\hline
\end{tabular}

Proporsi blending kualitas batubara untuk pemuatan pertama Galaxy Tujuan Filipina yaitu:

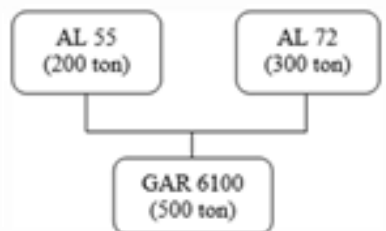

Gambar 4.2 Skema Pencampuran Kualitas dan Kuantitas Batubara untuk Pemuatan Pertama

1. Kapasitas Batubara untuk Pemuatan Pertama Galaxy Tujuan Filipina

Agar bisa memenuhi kualitas dan kuantitas dari permintaan konsumen, maka batubara yang digunakan untuk pengisian pertama yaitu ada dua jenis batubara yaitu batubara jenis AL-55 sebanyak 200 ton dan AL-72 sebanyak 300 ton jadi pengeluaran pengisian pertama untk pengiriman Galaxy Tujuan filipina sebanyak 500 ton (Tabel 4.5).

Tabel 4.5 Kapasitas Batubara yang digunakan untuk Pengiriman Pertama

\begin{tabular}{|c|c|c|c|c|c|c|c|}
\hline \multirow{2}{*}{ Parameter } & \multicolumn{5}{|c|}{ Mine Brand } & \multirow{2}{*}{$\begin{array}{c}\text { Total } \\
\text { Tonase } \\
\text { (ton) }\end{array}$} \\
\cline { 2 - 7 } & BAS-48 & BB-50 & AL-52 & AL-55 & AL-67 & AL-72 & 1.050 .656 \\
\hline $\begin{array}{c}\text { Stockpile } \\
\text { Awal }\end{array}$ & 299.083 & 477.710 & 32.000 & 16.909 & 74.500 & 150.454 & 1.00 \\
\hline Pengeluaran & - & - & - & 200 & - & 300 & 500 \\
\hline $\begin{array}{c}\text { Stockpile } \\
\text { Akhir }\end{array}$ & 299.083 & 477.710 & 32.000 & 16.709 & 74.500 & 150.154 & 1.050 .156 \\
\hline
\end{tabular}

2. Stockpile Sisa Pemuatan Pertama Ditambah dengan Pemasukan Batubara pada Stockpile

Stockpile ini merupakan batubara sisa dari pemuatan pertama, yaitu batubara sisa dari pemuatan yang akan digunakan untuk pemuatan kedua kemudian ditambah dengan batubara yang dikirim dari Tanjung Enim. Terdapat empat jenis batubara yang digunakan, yaitu BAS 48, BB 50, AL 52 dan AL 55, AL 67, AL 72 (Tabel 4.6).

Tabel 4.6 Stock Awal dan Pemasukan

\begin{tabular}{|c|c|c|c|c|c|c|c|}
\hline Parameter & \multicolumn{5}{|c|}{ Mine Brand } & \multirow{2}{*}{$\begin{array}{c}\text { Total } \\
\text { Tonase } \\
\text { (ton) }\end{array}$} \\
\hline Pemasukan & BAS-48 & BB-50 & AL-52 & AL-55 & AL-67 & AL-72 & 1.050 .156 \\
\hline Stock Awal & 299.083 & 477.710 & 32.000 & 16.709 & 74.500 & 150.154 & 1.00 \\
\hline 19-Mei-19 & 8.300 & 30.950 & 5.600 & 9.700 & 7.100 & 3.000 & 64.650 \\
\hline 20-Mei-19 & 16.350 & 29.000 & 1.700 & 2.150 & 11.500 & 7.600 & 68.300 \\
\hline Total & 323.733 & 537.660 & 39.300 & 28.559 & 93.100 & 160.754 & 1.183 .106 \\
\hline
\end{tabular}


Proporsi Blending Kualitas Batubara Untuk Pemuatan Kedua Galaxy Tujuan Filipina

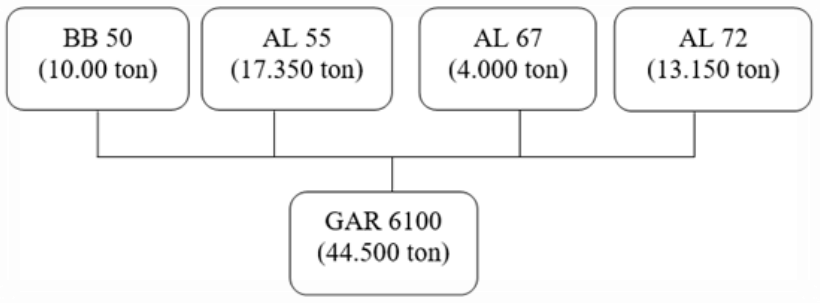

Gambar 4.3 Skema pencampuran kualitas dan kuantitas untuk pengisian kedua

3. Kapasitas batubara untuk pemuatan kedua Galaxy tujuan Filipina

Agar bisa memenuhi kualitas dan kuantitas dari permintaan konsumen, maka batubara yang digunakan untuk pemuatan kedua ini terdiri dari empat jenis batubara, yaitu batubara jenis BB-50 sebanyak 10.000 ton, AL-55 sebanyak 17.350 ton, AL-67 sebanyak 4.000 ton, dan AL-72 sebanyak 13.150 ton, jadi pengeluaran batubara untuk pengisian kedua untk pengiriman Galaxy Tujuan filipina sebanyak 44.500 ton (Tabel 4.9).

Tabel 4.7 Kapasitas Batubara yang digunakan

\begin{tabular}{|c|c|c|c|c|c|c|c|}
\hline \multirow{2}{*}{ Parameter } & \multicolumn{5}{|c|}{ Mine Brand } & $\begin{array}{c}\text { Total } \\
\text { Tonase } \\
\text { (ton) }\end{array}$ \\
\cline { 2 - 7 } & BAS-48 & BB-50 & AL-52 & AL-55 & AL-67 & AL-72 & 1.183 .106 \\
\hline $\begin{array}{c}\text { Stockpile } \\
\text { Awal }\end{array}$ & 323.733 & 537.660 & 39.300 & 28.559 & 93.100 & 160.754 & 1.06 \\
\hline Pengeluaran & - & 10.000 & - & 17.350 & 4.000 & 13.150 & 44.500 \\
\hline $\begin{array}{c}\text { Stockpile } \\
\text { Akhir }\end{array}$ & 323.733 & 527.660 & 39.300 & 11.209 & 89.100 & 147.604 & 1.138 .606 \\
\hline
\end{tabular}

Untuk Pemuatan Kedua

4. Stockpile Sisa Pemuatan Kedua Ditambah dengan Pemasukan Batubara pada Stockpile

Stockpile ini merupakan batubara sisa dari pemuatan kedua, yaitu batubara sisa dari pemuatan yang akan digunakan untuk pemuatan ketiga kemudian ditambah dengan batubara yang dikirim dari Tanjung Enim. Terdapat empat jenis batubara yang digunakan, yaitu BAS 48, BB 50, AL 52 dan AL 55, AL 67, AL 72 (Tabel 4.8)
Tabel 4.8 Stock Awal dan Pemasukan

\begin{tabular}{|c|c|c|c|c|c|c|c|}
\hline Parameter & \multicolumn{5}{|c|}{ Mine Brand } & \multirow{2}{*}{$\begin{array}{c}\text { Total } \\
\text { Tonase } \\
\text { (ton) }\end{array}$} \\
\hline Pemasukan & BAS-48 & BB-50 & AL-52 & AL-55 & AL-67 & AL-72 & A \\
\hline Stock Awal & 323.733 & 527.660 & 39.300 & 11.209 & 89.100 & 147.604 & 1.138 .606 \\
\hline 21-Mei-19 & - & 38.450 & 200 & - & 3.000 & - & 41.650 \\
\hline Total & 323.733 & 566.110 & 39.500 & 11.209 & 92.100 & 147.604 & 1.180 .256 \\
\hline
\end{tabular}

Proporsi Blending Kualitas Batubara Untuk pemuatan Ketiga Galaxy Tujuan Filipina.

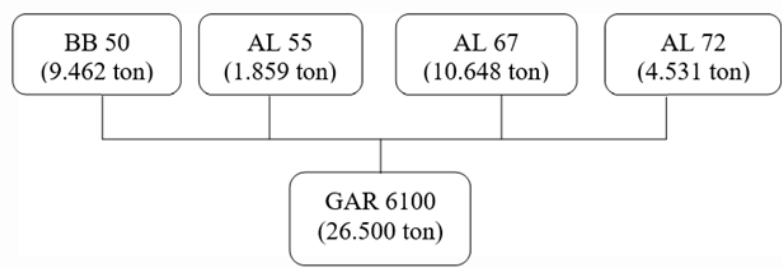

Gambar 4.4 Skema Pencampuran Kualitas dan Kuantitas untuk Pengisian Ketiga

5. Kapasitas batubara untuk pemuatan ketiga Galaxy tujuan Filipina

Agar bisa memenuhi kualitas dan kuantitas dari permintaan konsumen, maka batubara yang digunakan untuk pemuatan ketiga ini terdiri dari empat jenis batubara, yaitu batubara jenis BB-50 sebanyak 6.462 ton, AL-55 sebanyak 1.859 ton, AL-67 sebanyak 10.648 ton, dan AL-72 sebanyak 4.531 ton, jadi pengeluaran batubara untuk pengisian kedua untk pengiriman Galaxy tujuan Filipina sebanyak 26.500 ton (Tabel 4.11).

Tabel 4.9 Kapasitas Batubara yang digunakan Untuk Pemuatan Ketiga

\begin{tabular}{|c|c|c|c|c|c|c|c|}
\hline \multirow{2}{*}{ Parameter } & \multicolumn{5}{|c|}{ Mine Brand } & $\begin{array}{c}\text { Total } \\
\text { Tonase } \\
\text { (ton) }\end{array}$ \\
\cline { 2 - 7 } & BAS-48 & BB-50 & AL-52 & AL-55 & AL-67 & AL-72 & A \\
\hline $\begin{array}{c}\text { Stockpile } \\
\text { Awal }\end{array}$ & 323.733 & 566.110 & 39.500 & 11.209 & 92.100 & 147.604 & 1.180 .256 \\
\hline Pengeluaran & - & 9.462 & - & 1.859 & 10.648 & 4.531 & 26.500 \\
\hline $\begin{array}{c}\text { Stockpile } \\
\text { Akhir }\end{array}$ & 323.733 & 556.648 & 39.500 & 9.350 & 81.452 & 143.073 & 1.153 .756 \\
\hline
\end{tabular}




\subsection{Stock Akhir Batubara 31 Mei 2019}

Setelah pengiriman dilakukan, tahap selanjutnya adalah perhitungan dan analisis stock akhir. Stock akhir didapat dari stock awal di bulan Mei 2019 ditambah dengan pemasukan kemudian dikurang dengan jumlah pengiriman. Stock akhir ini akan menjadi stock awal pada bulan Juni 2019 (Tabel 4.10).

Tabel 4.10 Stock Akhir Batubara Bulan Mei 2019

\begin{tabular}{|l|r|r|r|r|r|r|r|}
\hline \multirow{2}{*}{\multicolumn{1}{c|}{ Parameter }} & \multicolumn{5}{|c|}{ Mine Brand } & \multirow{2}{*}{ Tonase } \\
\cline { 2 - 8 } & BAS-48 & BB-50 & \multicolumn{1}{|c|}{ AL-52 } & \multicolumn{1}{c|}{ AL-55 } & \multicolumn{1}{c|}{ AL-67 } & \multicolumn{1}{c|}{ AL-72 } & \\
\hline Stockpile Awal seluruh & 488.333 & 792.460 & 81.050 & 78.759 & 129.751 & 198.004 & 1.768 .356 \\
\hline Pengeluaran & & 19.462 & & 19.409 & 14.648 & 17.981 & 71.500 \\
\hline Stockpile Akhir & 488.333 & 772.998 & 81.050 & 59.350 & 115.103 & 180.023 & 1.696 .856 \\
\hline
\end{tabular}

\subsection{Proporsi Realisasi Blending dan Opsional Proporsi Blending}

Realisasi proporsi batubara untuk memenuhi kebutuhan ekspor tujuan Galaxy, Filipina. Berdasarkan Tabel merupakan realisasi proporsi pencampuran batubara yang dilakukan di PT Bukit Asam, Tbk. Unit Pelabuhan Tarahan, dan pada tabel tersebut peneliti membuat proporsi pencampuran batubara yang juga bisa digunakan sebagai optional oleh perusahaan.

Tabel 4.11 Proporsi Realisasi dan Opsional Blending batubara

\begin{tabular}{|c|r|r|}
\hline \multirow{2}{*}{ Jenis Batubara } & \multicolumn{2}{|c|}{ Galaxy } \\
\cline { 2 - 3 } & Realisasi (ton) & Opsional (ton) \\
\hline BAS-48 & - & \\
\hline BB-50 & 19.462 & 21.400 \\
\hline AL-52 & - & \\
\hline AL-55 & 19.409 & 16.400 \\
\hline AL-64 & - & 9.500 \\
\hline AL-67 & 14.648 & 9.000 \\
\hline AL-72 & 17.981 & 15.200 \\
\hline Total & \multicolumn{2}{|c}{71.500} \\
\hline
\end{tabular}

Pada tabel tersebut kita dapat melihat proposi optional yang diberikan peneliti, yaitu untuk memenuhi permintaan Galaxy proporsi yang digunakan BB-50 sebanyak 21.400 ton, AL-55 sebanyak 16.400 ton, AL-64 sebanyak 9.500 ton, AL-67 sebanyak 9.000 ton, AL-72 sebanyak 15.200 ton, dengan menggunakan proporsi tersebut kita dapat meningkatkan penggunaan batubara kualitas rendah dan penghematan batubara kualitas tinggi.

Kualitas yang didapat dengan proporsi realisasi dan optional hasil penelitian dapat dilihat di tabel berikut, pada tabel tersebut diterangkan ketercapaian kualitas dan kualitas dari batubara yang dicampurkan yang spesifikasinya sesuai dengan spesifikasi permintaan pasar.

Tabel 4.12 Kualitas Realisasi Blending dan Opsional Blending Batubara

\begin{tabular}{|l|c|c|c|}
\hline \multirow{2}{*}{ Parameter } & \multicolumn{3}{|c|}{ Galaxy (Filipina) } \\
\cline { 2 - 4 } & RKAP (Target) & Realisasi & Opsional \\
\hline Tonase (ton) & 70.000 & 71.500 & 71.500 \\
\hline Kalori (kkal/kg) & $6.100-6400$ & 6.262 & 6.164 \\
\hline Total Moisture (\%) & 17,78 (Max) & 16,88 & 17,17 \\
\hline Total Sulpur (\%) & 1,00 (Max) & 0,81 & 0,78 \\
\hline
\end{tabular}

\section{KESIMPULAN DAN SARAN}

\subsection{Kesimpulan}

Dari hasil penelitian dan pengamatan di lapangan maka didapatkan kesimpulan sebagai berikut :

1. Opsional proporsi pencampuran batubara hasil penelitian adalah sebagai berikut,

Pengiriman Galaxy, BB-50 sebanyak 21.400 ton, Al-55 sebanyak 16.400 ton, Al-64 sebanyak 9.500 ton, AL-67 sebanyak 9.000 ton, dan Al-72 sebanyak 15.200

2. Stock awal sebelum dilakukan blending batubara, yaitu 1.768.356 ton, kemudian dilakukan pengiriman ekspor tujuan Galaxy, Filiphina sebesar 71.500 ton, sehingga stock akhir setelah pengiriman ekspor batubara ke Filipina bulan Mei 2019 adalah 1.696.856 ton.

\subsection{Saran}

Kegiatan blending batubara di PT Bukit Asam, Tbk. Unit Pelabuhan Tarahan untuk memenuhi kebutuhan pasar ekspor dapat dilakukan dengan mengoptimalkan penggunaan batubara peringkat rendah sehingga lebih ekonomis, serta dapat memanfaatkan batubara yang tertumpuk atau belum terpakai agar meminimalisir waktu timbunan yang mana dapat meminimalkan penurunan kualitas dan kuantitas maupun 
risiko yang lainnya yang diakibatkan lamanya timbunan.'

\section{DAFTAR PUSTAKA}

American Society for Testing and Materials. 2002. Standard Quality of Coal Mining : ASTM Internasional.

Anonim. 2014. Coal Mining Company. http://www.bayan.com.sg/index.php/en/ 7 Oktober 2014.

Anonim. 2017. Informasi Jual Beli Batubara. https://idmining.wordpress.com/2017/07/03/in formasi-jual-beli-batubara/ 3 Juli 2017.

Bennylin. $2019 . \quad$ Batubara. https://Wikipedia.co.id/ 06 juli 2019.

Suparny, Eny. 2016. Kajian Optimalisasi Pencampuran Batubara Beda Kualitaas untuk Memenuhi Permintaan Konsumen Di PT Berau Coal, Kabupaten Berau Provinsi Kalimantan Timur. http://eprints.upnyk.ac.id/8707/ 11 November 2016.

Carpenter, Anne M. 1995. "Management Of Coal Stockpile”. IEA Coal Reseach.

Charles G. Schofield. 1978. "Homogenization/ Blending System Design and Control For Mineral Processing”. 1st Edition, Trans Tech Publication. Clausthere Zellerfeld Federal Republic of Company.

Saputra, D. Triantoro, A. Riawan. 2014. "Simulasi Blending Batubara Di Bawah Standar Kontrak Dalam Blending Dua Jenis Grade Beda Kualitas Pada PT Amanah Anugerah Adi Mulia Site Kintap”. Jurnal Fisika Flux. 11 (1)

Satuan Kerja Kendali Produk PT Bukit Asam. 2019. PT. Bukit Asam, Tbk Tarahan : Bandar Lampung.

Wahyudi., 2018. "Blending Memenuhi Permintaan Pasar Domestic di PT. Bukit Asam, Tbk. Unit Dermaga Kertapati”. 